\title{
Modelo multicritério aditivo na geração de mapas de suscetibilidade à erosão em área rural
}

\author{
Gustavo Souza Valladares(1), Andréa da Silva Gomes(2), Fabio Enrique Torresan ${ }^{(3)}$, \\ Cristina Aparecida Gonçalves Rodrigues ${ }^{(3)}$ e Célia Regina Grego ${ }^{(3)}$
}

\begin{abstract}
(1)Universidade Federal do Piauí, Campus Ministro Petrônio Portela, Ininga, CEP 64049-550 Teresina, PI. E-mail: valladares@ufpi.edu.br (2)Universidade Federal Rural do Rio de Janeiro, BR 465, Km 7, CEP 23890-000 Seropédica, RJ. E-mail: andrea_zooufc@yahoo.com.br ${ }^{(3)}$ Embrapa Monitoramento por Satélite, Avenida Soldado Passarinho, no 303, Fazenda Chapadão, CEP 13070-115 Campinas, SP. E-mail: torresan@cnpm.embrapa.br, crisagr@cnpm.embrapa.br, crgrego@cnpm.embrapa.br
\end{abstract}

Resumo - O objetivo deste trabalho foi avaliar a geração de um mapa de suscetibilidade à erosão, em área rural, no Município de Guararapes, SP, por meio de modelo multicritério aditivo. Foram utilizados mapas digitais dos temas: relevo (declividade e comprimento das rampas); pedologia (obtida em campo); uso e cobertura das terras da região; e interpretação do modelo digital de elevação. Os mapas digitais foram tratados em ambiente de sistema de informação geográfica, por meio do método multicritério aditivo, e validados pelo modelo da equação universal de perda de solo (USLE). Foram geradas cinco classes de suscetibilidade à erosão: baixa, moderada, alta, muito alta e altíssima. O mapa de risco obtido por multicritério aditivo teve boa correspondência com o modelo USLE. O mapa de suscetibilidade à erosão pode ser aplicado ao planejamento agrícola e ambiental da área rural do Município de Guararapes.

Termos para indexação: geoprocessamento, EUPS, risco ambiental.

\section{Multicriteria additive model in generating maps of susceptibility to erosion in rural area}

\begin{abstract}
The objective of this work was to evaluate the construction of an erosion susceptibility map for a rural area of the municipality of Guararapes, SP, Brazil, using a multicriteria additive model. Digital maps on the themes relief (declivity and length of the slopes), pedology (obtained at the field), land use and land cover of the region, and interpretation of the digital elevation model were used. The digital maps were treated in a geographic information system environment using the additive multicriteria method and were validated by the universal soil loss equation (USLE) model. Five erosion susceptibility classes were generated: low, moderate, high, very high, and extremely high. The risk map obtained by additive multicriteria had good correspondence with the USLE model. The erosion susceptibility map can be used for the agricultural and environmental planning of the rural area of the municipality of Guararapes.
\end{abstract}

Index terms: geoprocessing, USLE, environmental risk.

\section{Introdução}

O uso e a ocupação de terras em áreas consideradas vulneráveis, sob o ponto de vista agrícola, têm aumentado o processo de perda de solo que ocorre naturalmente, em decorrência da associação do clima com os tipos de litologia, relevo, solo e cobertura vegetal (Spörl \& Ross, 2004; Mota \& Valladares, 2011). A falta de planejamento do uso do solo pode levar a processos erosivos em intensidade e velocidade que ultrapassam os limites de tolerância (Mello et al., 2006). Uma vez que a degradação dos solos afeta a sustentabilidade dos agroecossistemas (Navas et al., 2005), as práticas de conservação do solo e os métodos de avaliação de impactos ambientais e de perdas de solo surgem como importantes ferramentas no planejamento agroambiental.

A equação universal de perda de solo (USLE) é um modelo multiplicativo e um dos mais eficientes modelos de estimativa de perdas de solo. Nesta equação, os fatores naturais mais importantes estão ligados ao clima, ao solo, à morfologia do terreno, e a fatores associados ao manejo (características da cultura) e à ocupação da terra (Wischmeier \& Smith, 1978). A USLE é representada por: $A=R * K * L S * C * P$ em que A é a estimativa de solo perdido por erosão; R é o fator erosividade das chuvas; Ké o fator erodibilidade dos solos; LS é o fator do relevo que representa o

Pesq. agropec. bras., Brasília, v.47, n.9, p.1376-1383, set. 2012 
comprimento das pendentes e a declividade; $\mathrm{C}$ é o fator de uso e cobertura das terras; e P é o fator referente ao manejo empregado no solo.

A inclusão de métodos empíricos para o uso e a validação de novos modelos aplicados aos estudos de erosão e degradação dos solos é importante (Cohen et al., 2005). No mapeamento de risco ambiental voltado ao planejamento, têm sido empregados métodos multicritério aditivos, com resultados satisfatórios (Dias et al., 2003, 2006; Valladares \& Faria, 2004; Rahman et al., 2009; Yesilnacar et al., 2012).

As características pedológicas de maior importância para estudos erosivos são aquelas relacionadas à capacidade de infiltração da água no solo e à capacidade do solo em resistir ao destacamento e arraste de partículas pelo escoamento. Características do solo, como porosidade e grau de agregação, afetam diretamente a capacidade de infiltração e o escoamento superficial. Algumas destas características encontramse associadas, de forma qualitativa, à taxonomia dos solos (Reis et al., 2006).

O relevo representa outro aspecto de fundamental importância ao entendimento e à quantificação do processo erosivo, em que a declividade e o comprimento de encosta são os principais fatores relacionados à erosão. A declividade influencia, principalmente, a energia de escoamento. Quanto maior a declividade do terreno, sob as mesmas condições de solo e precipitação, menor será o volume de água que efetivamente se infiltrará no solo e, consequentemente, maior o volume e a energia associada ao escoamento (Reis et al., 2006).

A declividade e o comprimento de rampa são parâmetros muito utilizados nos estudos e nas recomendações de controle de erosão, e estão inseridos em modelos de predição de perdas de solo ( $\mathrm{Lu}$ et al., 2004). O uso e a cobertura das terras também são fatores que influenciam o risco de erosão, tanto pelo tipo de cobertura como pelo manejo ao qual o solo é submetido.

A degradação ambiental gera processos erosivos que tornam os solos menos produtivos e o ambiente desequilibrado; portanto, o controle e o monitoramento da erosão são essenciais para o estabelecimento de qualquer uso do solo (Xavier et al., 2010). O levantamento do uso do solo é um aspecto primordial para qualquer ação de planejamento do território e para a gestão dos recursos naturais (Déstro \& Campos,
2006). A utilização do sistema de informação geográfica (SIG) facilita a manipulação e o cruzamento de dados espacializados do meio físico e socioeconômico, e favorece o diagnóstico e a caracterização de territórios de interesse. Assim, modelos gerados que refletem a realidade ambiental, como os estudos de suscetibilidade à erosão dos solos, fornecem apoio a decisões de planejamento e adequação do uso das terras.

O objetivo deste trabalho foi avaliar a geração de um mapa de suscetibilidade à erosão, em área rural, no Município de Guararapes, SP, por meio de modelo multicritério aditivo.

\section{Material e Métodos}

A área rural avaliada localiza-se no Município de Guararapes, no centro-oeste do Estado de São Paulo $\left(21^{\circ} 15^{\prime}\right.$ e $21^{\circ} 28^{\prime} \mathrm{S} ; 50^{\circ} 35^{\prime}$ e $\left.50^{\circ} 45^{\prime} \mathrm{W}\right)$. A precipitação anual média é de $1.391 \mathrm{~mm}$, com chuvas concentradas de setembro a março. O clima é do tipo Aw, conforme Köppen, considerado quente, com inverno seco e médias anuais de $27^{\circ} \mathrm{C}$. A área de estudo ocupa 11.020 ha e é constituída por solos originários de arenitos muito finos, siltosos e siltitos arenosos de coloração cinza-esverdeado (Batezelli et al., 2003). As classes de relevo predominantes são: suave ondulado, ondulado e plano. A altitude varia de 368 a $502 \mathrm{~m}$.

Foram delimitadas, em campo, três unidades de mapeamento de solos: LV1, Latossolo Vermelho eutrófico típico, com horizonte A moderado e textura média; PVA1, associação de Argissolo Vermelho-Amarelo e Argissolo Vermelho, ambos eutróficos típicos e lépticos, com horizonte Amoderado, textura arenosa/média e média; e PV1, associação de Argissolo Vermelho eutrófico típico, com horizonte A moderado, textura média e arenosa/média, e Latossolo Vermelho eutrófico típico e cambissólico, com horizonte A moderado e textura média.

O mapa pedológico foi produzido com base nas cartas topográficas, na escala 1:50.000, e em imagens Landsat TM 5, bandas 3, 4 e 5, com uso de metodologia convencional em nível de semidetalhe (Figura 1). O fator LS foi gerado em ambiente SIG, de acordo com Mitasova \& Mitas (1999).

O modelo digital de elevação foi gerado a partir do mapa topográfico digitalizado, na escala 1:50.000 e no formato vetorial. Para gerar o mapa de declividade em graus, foram utilizadas as funções "toporaster" e "slope" do programa ArcGIS. A função "raster 
calculator" foi usada para gerar o mapa do fator LS, para a área de estudo, conforme a equação, $\mathrm{LS}=(\mathrm{C} / 22,13)^{0,6} \times(\sin \mathrm{D} / 0,09)^{1,3}$, em que: $\mathrm{C}$ é o tamanho do pixel e $\mathrm{D}$ é o declive em graus. $\mathrm{O}$ tamanho do pixel foi de $25 \mathrm{~m}$.

O mapa de uso e cobertura das terras foi gerado com base em imagens Landsat TM 5, bandas 3, 4 e 5, por meio de classificação supervisionada (Figura 2). Já as classes de uso e cobertura das terras, foram geradas a partir de geotecnologias e imagens orbitais, o que possibilitou a quantificação das classes mapeadas. Toda a área foi percorrida para coleta de amostras de controle. As classes de uso e cobertura, pastagens, cana-de-açúcar, solo exposto e mata ciliar, representaram $92,3 \%$ da área total de estudo. A maior área foi a de pastagens $(45,4 \%)$.

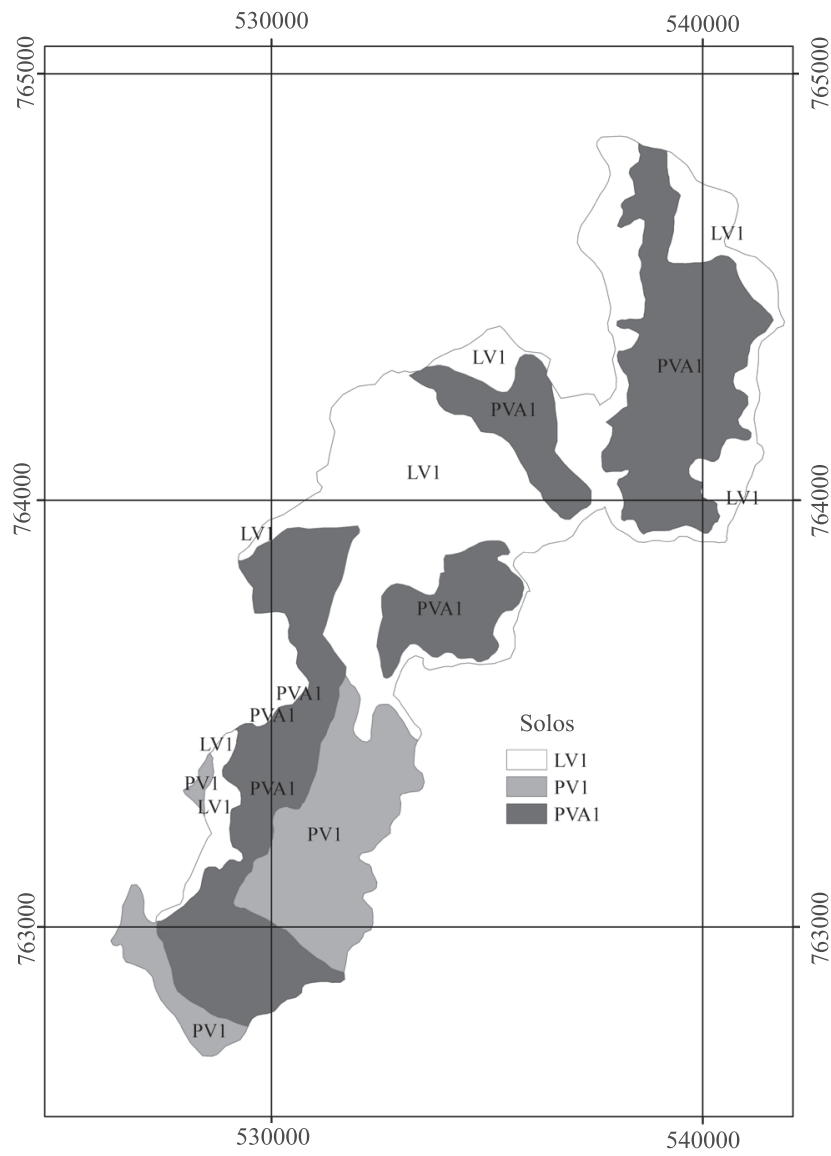

Figura 1. Mapa de solos da área de estudo no Município de Guararapes, SP. LV1, Latossolo Vermelho eutrófico típico; PV1, associação de Argissolo Vermelho eutrófico típico e Latossolo Vermelho eutrófico típico e cambissólico; PVA1, associação de Argissolo Vermelho-Amarelo e Argissolo Vermelho.
O mapa foi gerado com uso de método multicritério aditivo, definido por Silva \& Zaidan (2004) como média ponderada. $\mathrm{O}$ algoritmo recomendado, adequado aos mapas "raster" utilizados, foi: $\mathrm{Aij}=\Sigma(\mathrm{Pk} \times \mathrm{Nk})$ em que Aij é qualquer célula da matriz (alternativa) de acordo com o número de parâmetros envolvidos, que variam de i a j; P é o peso atribuído ao parâmetro, transposto o percentual para a escala de 0 a $1 ; \mathrm{k}=1$; e $\mathrm{N}$ é a nota na escala de 0 a 10 , atribuída à categoria encontrada na célula.

Para a realização das avaliações, foi utilizado algoritmo classificador, aplicável a uma estrutura de matrizes, no qual cada célula correspondeu a uma unidade territorial. A importância de cada evento analisado foi considerada em função do somatório dos produtos dos pesos relativos das variáveis escolhidas, multiplicado pelas notas das classes em cada unidade da célula.

O mapa de suscetibilidade à erosão foi gerado por meio de método multicritério, tendo-se considerado

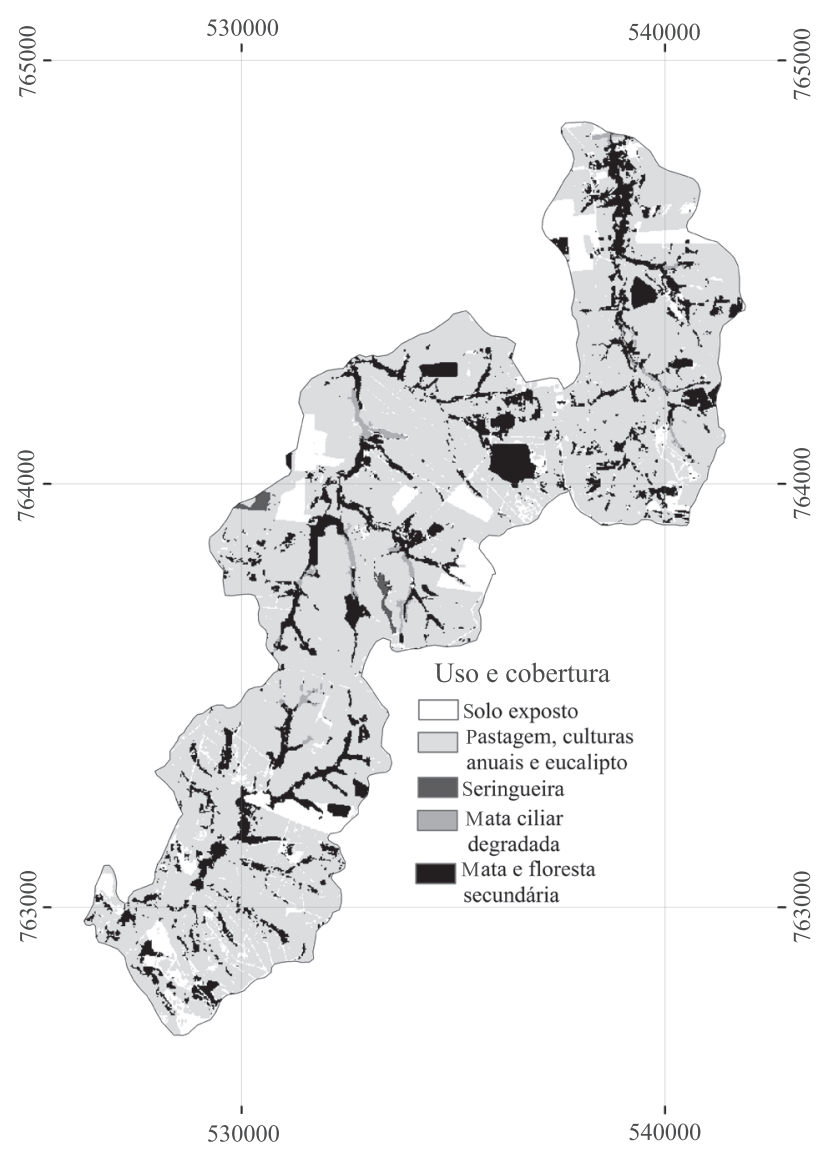

Figura 2. Mapa de uso e cobertura da área de estudo na região de Guararapes, SP. 
peso de $50 \%$ para o tema (critério) pedologia, de $30 \%$ para uso e cobertura das terras e de $20 \%$ para o fator do relevo LS. As notas de suscetibilidade à erosão foram atribuídas às unidades de mapeamento em escala de $0 \mathrm{a}$ 10 , o que indicou que quanto maior a nota, maior o risco de erosão da unidade de mapeamento. Foram definidas cinco classes para cada um dos mapas de suscetibilidade à erosão: baixa, moderada, alta, muito alta e altíssima. Para a delimitação espacial, utilizou-se a divisão de áreas por meio de quantis. Portanto, cada classe de suscetibilidade à erosão ocupou a mesma área.

O mapa de solos recebeu as seguintes notas: unidade LV1, nota 3; unidade PVA1, nota 6; e unidade PV1, nota 5. As notas para o mapa de uso e cobertura das terras foram: mata/floresta secundária $=1$; seringueira $=3$; eucalipto $=4$; culturas anuais/pastagem $=4$; mata ciliar degradada $=7$; e solo exposto $=10$.

O "raster" do fator LS foi classificado em 11 classes segundo o método de quebras naturais (Jenks) do ArcGIS e reclassificado de 0 a 10 , sendo estas as notas assumidas (Figura 3).

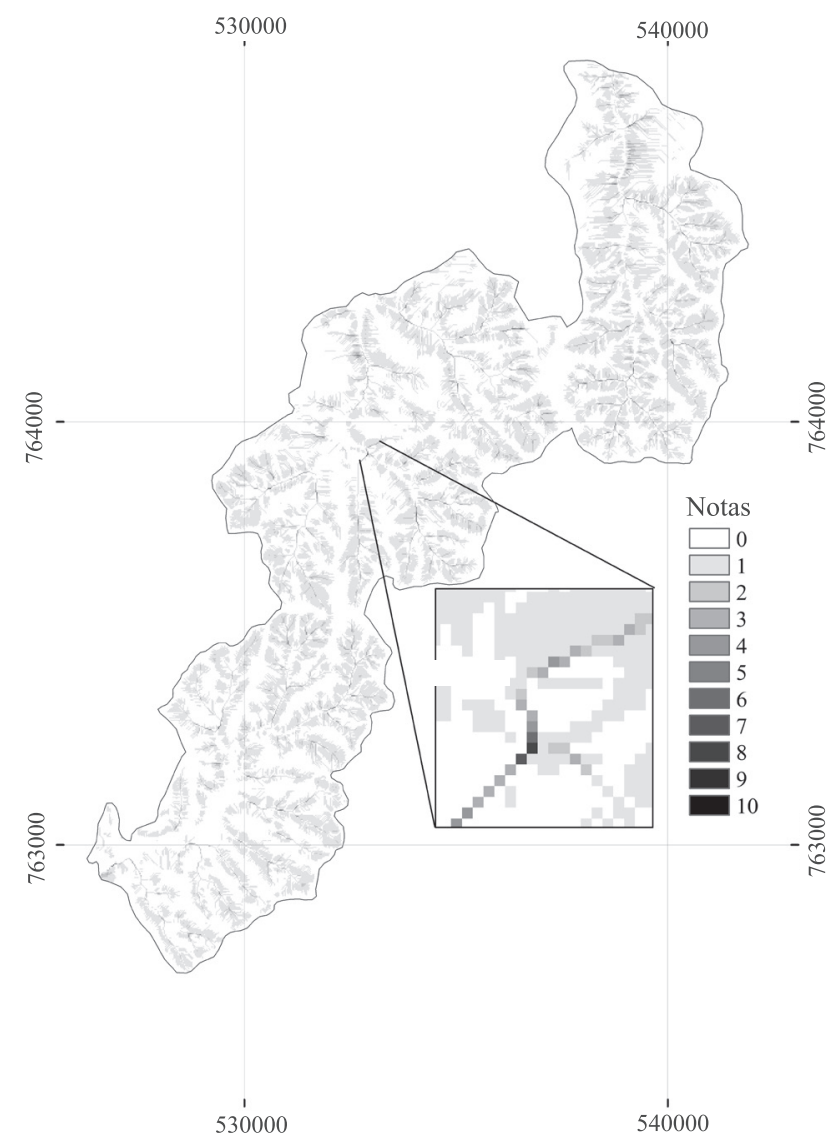

Figura 3. Notas atribuídas ao fator do relevo (LS) na área rural de Guararapes, SP.
Gerou-se um segundo mapa de classes de suscetibilidade à erosão, por meio do método multiplicativo da USLE, para validação do método multicritério aditivo utilizado. Os fatores da USLE considerados foram K, LS, C e P. Como o mapa gerado pelo modelo multiplicativo não teve a finalidade de estimar a perda de solo, foram empregados os mesmos valores para os fatores $\mathrm{K}$, LS e C, considerados no mapa aditivo. $\mathrm{O}$ fator $\mathrm{P}$ foi considerado 1 para solo exposto; 0,75 para mata ciliar degradada; 0,5 para culturas anuais; 0,3 para pastagem; 0,25 para culturas florestais, como eucalipto e seringueira; e 0,1 para áreas de mata e floresta (Renard et al., 1997; Bertoni \& Lombardi Neto, 2012).

\section{Resultados e Discussão}

A área classificada com baixa suscetibilidade à erosão foi representada por solos da unidade LV1, principalmente por Latossolos nos topos e nos terços superiores da paisagem (Figura 4). Esses solos apresentam baixo gradiente textural, são profundos ou muito profundos, normalmente porosos e bem estruturados, o que lhes proporciona alta permeabilidade. Por ocorrerem nas áreas mais planas da paisagem, essas características favorecem a infiltração da água e minimizam o escoamento superficial e, portanto, os processos erosivos.

A baixa relação textural e a estrutura bem desenvolvida desses solos facilitam a drenagem de água no perfil, fatores que, aliados à sua textura argilosa ou muito argilosa, conferem-lhes maior resistência à erosão (Bertol \& Almeida, 2000; Cerdan et al., 2010). A mineralogia oxídica dos Latossolos favorece boa estruturação e é um dos motivos da sua baixa erodibilidade (Silva et al., 2009).

Do resultado da sobreposição do mapa de suscetibilidade à erosão com o de uso e cobertura das terras (Figuras 2 e 4), os usos e coberturas mais comuns da classe baixa são as culturas de milho $(61,5 \%$ da área total dessa classe de uso e cobertura, na área de estudo), seringueira $(38,2 \%)$ e eucalipto $(55,1 \%)$, com alguns remanescentes de vegetação nativa. Durante a maior parte do tempo, estes solos apresentam-se cobertos, o que minimiza os processos erosivos (Castro Filho \& Logan, 1991; Cunha \& Guerra, 2003a).

A classe moderada ocorreu na unidade LV1 em posição da paisagem semelhante à da classe de 
suscetibilidade baixa, porém em áreas de declive mais acentuado e pendentes longas (Figura 4). Essa classe também ocorreu na unidade PV1, desde o terço inferior da paisagem até o terço superior, em declives suaves. Os Argissolos, de maneira geral (unidade PV1), apresentam elevado gradiente textural, menor grau de floculação e menor porosidade no horizonte B quando comparados aos Latossolos. A maior concentração de argila em subsuperfície causa redução da velocidade de infiltração em relação aos horizontes mais superficiais, propriedade que aumenta a suscetibilidade natural à erosão desses solos (Bortoluzzi et al., 2008). A gênese do gradiente textural nos Argissolos está associada à intensa morfogênese (Carvalho Júnior et al., 2008). Os Argissolos, mesmo com boa agregação e estruturação, apresentam certa vulnerabilidade à erosão, sobretudo quando ocorrem descontinuidades texturais (Cunha \& Guerra, 2003b).

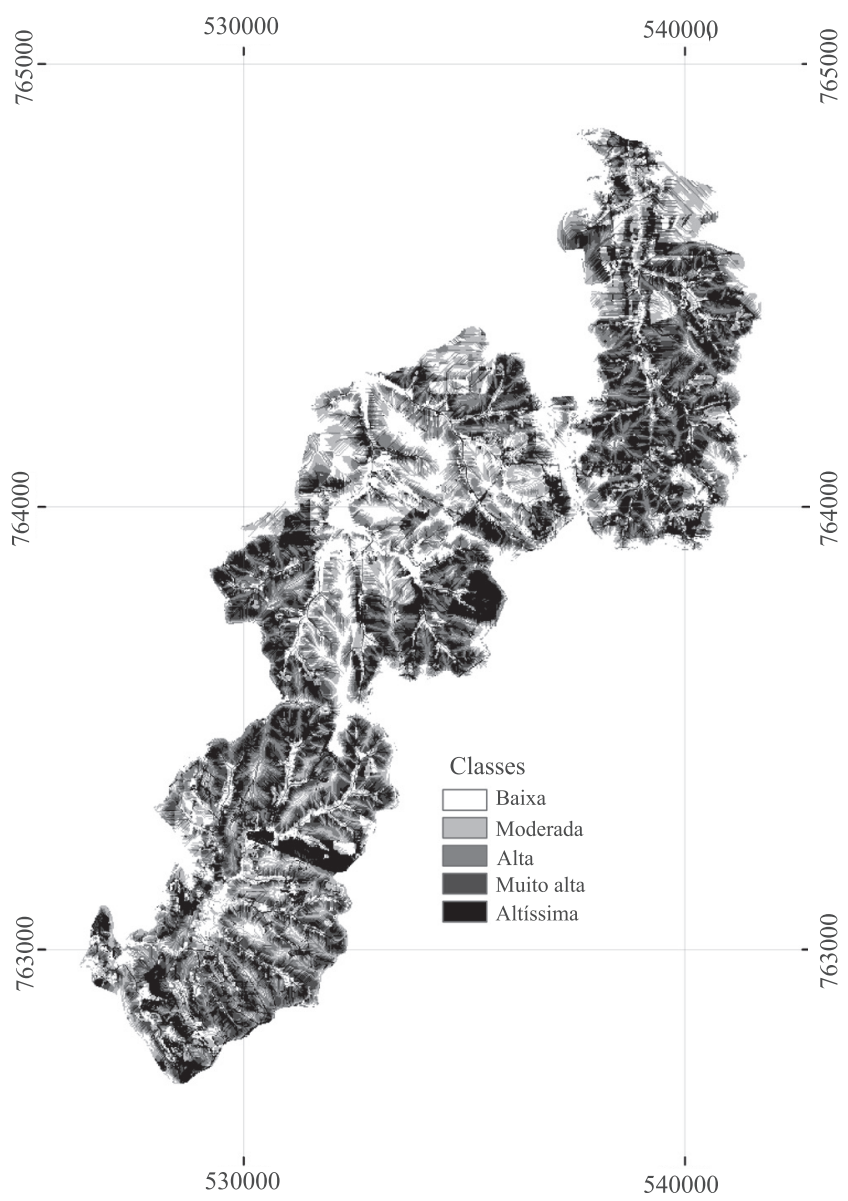

Figura 4. Classes de susceptibilidade à erosão, na área rural de Guararapes, SP, geradas pelo modelo da equação universal de perda de solo.
As classes de suscetibilidade alta e muito alta ocorreram em áreas adjacentes à classe moderada na unidade PV1, embora em relevos mais declivosos, o que aumenta a erodibilidade dos solos (Figura 4). À medida que aumenta a declividade de uma área, também ocorre aumento no risco de erosão. Segundo Bertoni \& Lombardi Neto (2012), a topografia, representada pela declividade e pelo comprimento das pendentes, tem grande influência sobre a erosão. O tamanho e a quantidade do material em suspensão arrastado pela água dependem da intensidade do fluxo e do refluxo da drenagem, que é representado pelo grau de declive do terreno, e determinam a potencialidade da erosão (Tundisi et al., 2006; Batistella \& Valladares, 2009).

Essas classes também ocorrem na unidade PVA1, com a presença de Argissolos típicos e Argissolos lépticos, que indicam contato com a rocha a profundidades inferiores a $1 \mathrm{~m}$, o que caracteriza elevada morfogênese. A classe de risco muito alto ocorre em posições semelhantes às da classe alta, mas com maior declive ou comprimento das pendentes. Diferentes usos dos solos causaram diferenciação nestas classes, sendo o uso menos conservacionista classificador de solos com suscetibilidade muito alta, como pastagens $(41,1 \%$ da área total dessa classe) e cana-de-açúcar (41,3\%). Essas áreas devem ser manejadas com cuidado, ao se considerar os métodos de manejo para conservação dos solos.

A classe de suscetibilidade altíssima inclui solos muito declivosos com comprimentos de rampa mais longos e naturalmente mais susceptíveis à erosão. Portanto, qualquer alteração antrópica pode acelerar o processo erosivo. Essa classe ocorre, principalmente, nas calhas dos rios e córregos e nas suas adjacências. Quanto ao uso e à cobertura das terras, apresenta algumas porções da área com mata/floresta secundária, o que minimiza os impactos dos processos erosivos, devido a grande cobertura do solo seja pela vegetação ou os restos orgânicos na superfície. Segundo Bertoni \& Lombardi Neto (2012), há uma diferença considerável entre as quantidades de perdas por erosão, para cada tipo de cultura; por exemplo, a mata é mais eficiente para evitar a perda de solo e de água do que uma plantação de algodão. No entanto, por apresentarem solos muito declivosos, com comprimentos de pendentes mais longos e naturalmente mais susceptíveis à erosão, estas áreas foram classificadas como de altíssimo risco de erosão. Dessa forma, em concordância com Diniz et al. 
(2008), observou-se que a declividade foi o fator mais determinante na erodibilidade dessas áreas, mesmo com o auxílio de outras variáveis na determinação do grau de erosão, como, por exemplo, os temas pedologia e uso e cobertura das terras.

Entre os fatores da USLE, o fator topográfico (LS) é considerado um dos principais responsáveis pelas perdas de solo, que representa o efeito combinado do comprimento e do grau de declive da encosta (Bertoni \& Lombardi Neto, 2012; Garcia Rodriguez \& Gimenez Suarez, 2012). Chaves (2010), ao avaliar as incertezas referentes ao emprego da USLE, verificou que, em áreas mais susceptíveis à erosão, o emprego de terraços minimizou as perdas de solo por erosão e aumentou a confiabilidade do modelo matemático utilizado na estimativa de perda de solo.

Nas classes baixa e moderada, de risco à erosão, geradas pelo método aditivo (Figura 5), a mata, o

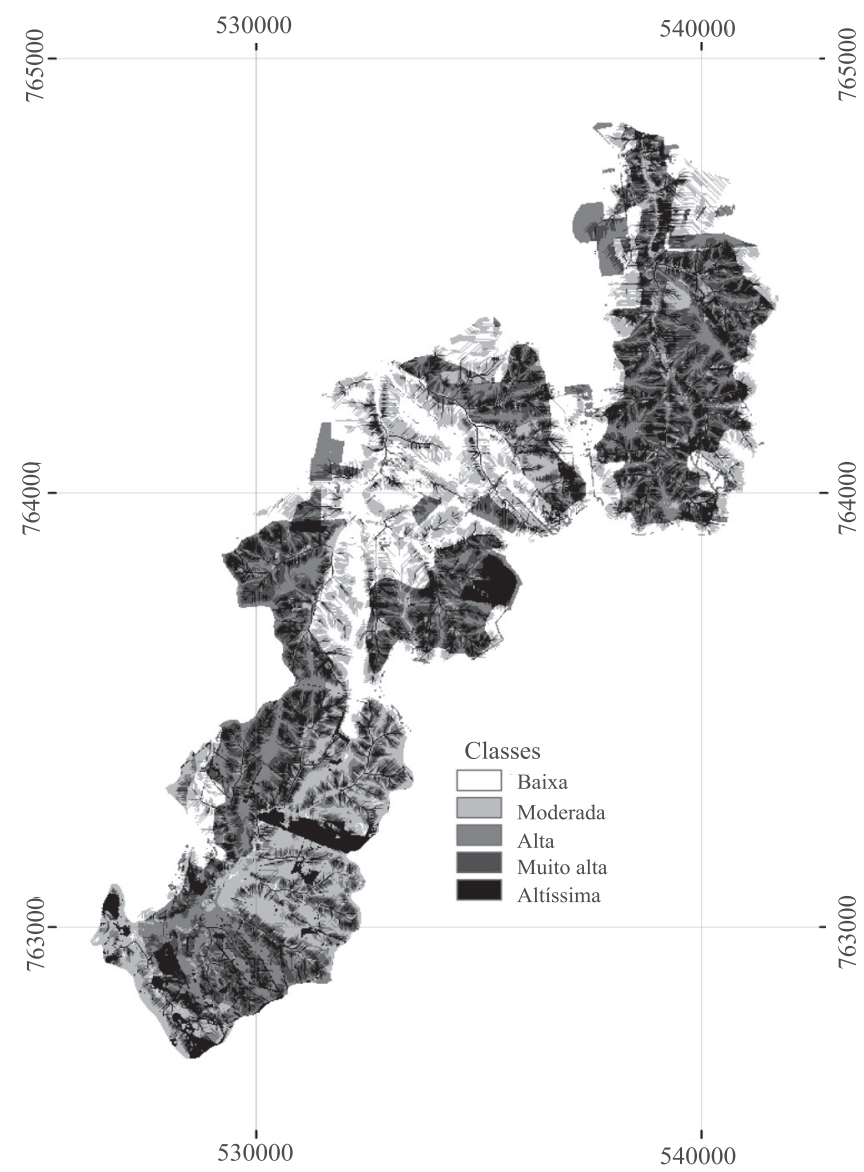

Figura 5. Classes de susceptibilidade à erosão, na área rural de Guararapes, SP, geradas pelo modelo multicritério aditivo. milho, a silvicultura e o eucalipto representaram, respectivamente, 54,6, 89,6, 64,9 e 90,3\% da área total de cada uma dessas classes de uso e cobertura, na área de estudo. Nas classes alta, muito alta e altíssima, as classes de uso e cobertura pastagens, cana-de-açúcar, solo exposto, mata ciliar e mata ciliar degradada representaram, respectivamente, 55,8, 56,6, 82,9, 68,6 e $70,4 \%$.

Ao se comparar os mapas de suscetibilidade à erosão, gerados pelas duas metodologias, notou-se semelhança entre os mapas quanto à correspondência da distribuição espacial das diferentes classes (Figuras 4 e 5). As classes de mais risco, no caso, muito alto e altíssimo, apresentam correspondência entre áreas (Tabela 1). Quando ocorreu divergência entre as classes, a maior parte das áreas foi atribuída à classe adjacente. Ao se utilizar as cinco classes, os mapas tiveram índice de acurácia Kappa de 0,4, considerado moderado.

Do ponto de vista do uso dos mapas gerados como ferramenta de planejamento, o método aditivo se mostrou mais adequado, em razão da maior uniformidade dos polígonos das classes e da maior similaridade entre os polígonos adjacentes. O modelo USLE necessita de uma filtragem ou interpolação para gerar um mapa com classes mais homogêneas e de fácil aplicação ao planejamento (Figura 5). O efeito de maior dispersão espacial das classes foi gerado, principalmente, pelo fator LS, que apresentou as maiores amplitudes. No modelo aditivo, a redução do fator USLE, em menos classes e com amplitudes milhares de vezes menores, favoreceu a geração de um mapa com menor variabilidade de classes com suscetibilidade à erosão.

Tabela 1. Correspondência entre as áreas (\%) das classes de susceptibilidade à erosão geradas pelo modelo da equação universal de perda de solo (USLE) e pelo modelo multicritério aditivo.

\begin{tabular}{lrrrcc}
\hline Classes do & \multicolumn{5}{c}{ Classes do modelo USLE } \\
\cline { 2 - 6 } modelo aditivo & Baixa & Moderada & Alta & Muito alta & Altíssima \\
\hline Baixa & 57,8 & 20,1 & 16,6 & 3,5 & 2,0 \\
Moderada & 26,2 & 34,6 & 18,6 & 13,8 & 6,9 \\
Alta & 2,2 & 43,2 & 29,4 & 14,2 & 11,0 \\
Muito alta & 1,5 & 4,2 & 19,2 & 66,2 & 8,8 \\
Altíssima & 0,2 & 4,3 & 3,6 & 21,8 & 70,2 \\
\hline
\end{tabular}




\section{Conclusões}

1. O emprego do modelo multicritério aditivo é eficiente na geração de mapa de suscetibilidade à erosão, para área rural, no Município de Guararapes, SP.

2. O mapa de suscetibilidade à erosão pode ser aplicado ao planejamento agrícola e ambiental na área rural de Guararapes.

\section{Agradecimentos}

Ao Conselho Nacional de Desenvolvimento Científico e Tecnológico, pelo apoio financeiro e concessão de bolsa.

\section{Referências}

BATEZELLI, A.; SAAD, A.R.; ETCHEBEHERE, M.L. de C.; PERINOTTO, J.A. de J.; FULFARO, V.J. Análise estratigráfica aplicada à formação Araçatuba (Grupo Bauru - $\mathrm{k}_{\mathrm{s}}$ ) no centro-oeste do Estado de São Paulo. Geociências, v.2, p.5-19, 2003.

BATISTELLA, M.; VALLADARES, G.S. Farming expansion and land degradation in Western Bahia, Brazil. Biota Neotropica, v.9, p.61-76, 2009.

BERTOL, I.; ALMEIDA, J.A. Tolerância de perda de solo por erosão para os principais solos do Estado de Santa Catarina. Revista Brasileira de Ciência do Solo, v.24, p.657-668, 2000.

BERTONI, J.; LOMBARDI NETO, F. Conservação do solo. 8.ed. São Paulo: Ícone, 2012. 360p.

BORTOLUZZI, E.C.; PERNES, M.; TESSIER, D. Mineralogia de partículas envolvidas na formação de gradiente textural em um Argissolo subtropical. Revista Brasileira de Ciência do Solo, v.32, p.997-1007, 2008.

CARVALHO JUNIOR, W. de; SCHAEFER, C.E.G.R.; CHAGAS, C. da S.; FERNANDES FILHO, E.I. Análise multivariada de Argissolos da faixa atlântica brasileira. Revista Brasileira de Ciência do Solo, v.32, p.2081-2090, 2008.

CASTRO FILHO, C.; LOGAN, T.J. Liming effects on the stability and erodibility of some Brazilian Oxisols. Soil Science Society of American Journal, v.55, p.1407-1413, 1991.

CERDAN, O.; GOVERS, G.; LE BISSONNAIS, Y.; VAN OOST, K.; POESEN J.; SABY, N.; GOBIN, A.; VACCA, A.; QUINTON, J.; AUERSWALD, K.; KLIK, A.; KWAAD, F.J.P.M.; RACLOT, D.; IONITA, I.; REJMAN, J.; ROUSSEVA, S.; MUXART, T.; ROXO, M.J.; DOSTAL, T. Rates and spatial variations of soil erosion in Europe: a study based on erosion plot data. Geomorphology, v.122, p.167-177, 2010.

CHAVES, H.M.L. Incertezas na predição da erosão com a USLE: impactos e mitigação. Revista Brasileira de Ciência do Solo, v.34, p.2021-2029, 2010.
COHEN, M.J.; SHEPHERD, K.D.; WALSH, M.G. Empirical reformulation of the universal soil loss equation for erosion risk assessment in a tropical watershed. Geoderma, v.124, p.235-252, 2005.

CUNHA, S.B. da; GUERRA, A.J.T. Degradação ambiental. In: GUERRA, A.J.T.; CUNHA, S.B. da. (Org.). Geomorfologia e meio ambiente. 4.ed. Rio de Janeiro: Bertrand Brasil, 2003a. p.337-379.

CUNHA, S.B. da; GUERRA, A.J.T. Geomorfologia do Brasil. 3.ed. Rio de Janeiro: Bertrand Brasil, 2003b. 23p.

DÉSTRO, G.F.G.; CAMPOS, S. Sig-Spring na caracterização do uso dos solos a partir de imagens do satélite CBERS. Energia na Agricultura, v.21, p.28-35, 2006.

DIAS, J.E.; GOMES, O.V.O; GOES, M.H.B. Áreas de riscos de enchentes no Município de Volta Redonda: uma aplicação por geoprocessamento. Caminhos de Geografia, v.1, p.13-25, 2003.

DIAS, J.E.; GOMES, O.V.O; GOES, M.H.B. Impacto ambiental de áreas susceptíveis a erosão do solo sobre áreas potenciais para pecuária no Município Volta Redonda-RJ. Ágora, v.13, p.31-42, 2006.

DINIZ, S.F.; MOREIRA, C.A.; CORRADINI, F.A. Susceptibilidade erosiva do baixo curso do Rio Acaraú - CE. Geociências, v.27, p.355-367, 2008.

GARCIA RODRIGUEZ, J.L.; GIMENEZ SUAREZ, M.C. Methodology for estimating the topographic factor LS of RUSLE3D and USPED using GIS. Geomorfology, v.175, p.98-106, 2012.

LU, D.; LI, G.; VALLADARES, G.S.; BATISTELLA, M. Mapping soil erosion risk in Rondônia, Brazilian Amazonia: using RUSLE, remote sensing and GIS. Land Degradation and Development, v.15, p.499-512, 2004.

MELLO, G. de; BUENO, C.R.P.; PEREIRA, G.T. Variabilidade espacial de perdas de solo, do potencial natural e risco de erosão em áreas intensamente cultivadas. Revista Brasileira Engenharia Agrícola Ambiental, v.10, p.315-322, 2006.

MITASOVA, H.; MITAS, L. Modeling soil detachment with RUSLE 3d using GIS. 1999. Available at: <http://skagit.meas. ncsu.edu/ helena/gmslab/erosion/usle.html $>$. Accessed on: 15 May 2010.

MOTA, L.H. da S. de O.; VALLADARES, G.S. Vulnerabilidade à degradação dos solos da Bacia do Acaraú, Ceará. Revista Ciência Agronômica, v.42, p.39-50, 2011.

NAVAS, A.; MACHIN, J.; SOTO, J. Assessing soil erosion in a Pyrenean mountain catchment using GIS and fallout ${ }^{137} \mathrm{Cs}$. Agriculture, Ecosystems and Environment, v.105, p.493-506, 2005.

RAHMAN, M.R.; SHI, Z.H.; CHONGFA, C. Soil erosion hazard evaluation - an integrated use of remote sensing, GIS and statistical approaches with biophysical parameters towards management strategies. Ecological Modelling, v.220, p.1724-1734, 2009.

REIS, M.H. dos; GRIEBELER, N.P.; SOUZA, P.T.M. de; RABELO, M.W. de O. Mapeamento de áreas de risco à ocorrência da erosão hídrica no Sudoeste Goiano com base na distribuição espacial de chuvas intensas. In: SIMPÓSIO DE GEOTECNOLOGIAS NO 
PANTANAL, 1., 2006, Campo Grande. Anais. Campo Grande: Embrapa Informática Agropecuária: INPE, 2006. p.219-228.

RENARD, K.G.; FOSTER, G.R.; WEESIES, G.A.; MCCOOL, D.K.; YODER, D.C. (Coord.). Predicting soil erosion by water: a guide to conservation planning with the Revised Universal Soil Loss Equation (RUSLE). Washington: USDA, 1997. 404p. (USDA. Agriculture handbook, 703).

SILVA, A.M.; SILVA, M.L.N.; CURI, N.; AVANZI, J.C.; FERREIRA, M.M. Erosividade da chuva e erodibilidade de Cambissolo e Latossolo na região de Lavras, sul de Minas Gerais.

Revista Brasileira de Ciência do Solo, v.33, p.1811-1820, 2009.

SILVA, J.X. da; ZAIDAN, R.T. (Org.). Geoprocessamento e análise ambiental: aplicações. Rio de Janeiro: Bertrand Brasil, 2004. 368p.

SPÖRL, C.; ROSS, J.L.S. Análise comparativa da fragilidade ambiental com aplicação de três modelos. GEOUSP - Espaço e Tempo, n.15, p.39-49, 2004.

TUNDISI, J.G.; TIZIANI, V.; NAKASU, L. Plano de desenvolvimento sustentável do Vale do Acaraú-Plandesva.
In: FALCÃO SOBRINHO, J.; FALCÃO, C.L. da. C. (Org.). Semi-Árido: diversidades, fragilidades e potencialidades. Sobral: Sobral Gráfica, 2006. p.194-212.

VALLADARES, G.S.; FARIA, A.L.L. SIG na análise do risco de salinização na Bacia do Rio Coruripe, AL. Engevista, v.6, p.86-98, 2004.

WISCHMEIER, W.H.; SMITH, D.D. Predicting rainfall erosion losses: a guide to conservation planning. Washington: USDA, 1978. 57p. (USDA. Agricultural handbook, 537).

XAVIER, F.V.; CUNHA, K.L.; SILVEIRA, A.; SALOMÃO, F.X.T. Análise da suscetibilidade à erosão laminar da Bacia do Rio Manso, Chapada dos Guimarães, MT, utilizando Sistemas de Informações Geográficas. Revista Brasileira de Geomorfologia, v.11, p.51-60, 2010.

YESILNACAR, M.I.; SÜZEN, M.L.; KAYA, B.S.; DOYURAN, V. Municipal solid waste landfill site selection for the city of Şanliurfa-Turkey: an example using MCDA integrated with GIS. M. International Journal of Digital Earth, v.5, p.147-164, 2012.

$\overline{\text { Recebido em } 30 \text { de agosto de } 2011 \text { e aprovado em } 30 \text { de agosto de } 2012}$ 